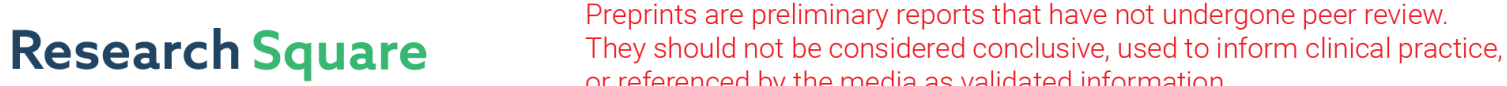 or referenced by the media as validated information. \\ Half-Life Modeling of Basic Fibroblast Growth Factor and its Media Concentration from Growth Factor-Eluting Polyelectrolyte Multilayers
}

Ivan Ding

University of Massachusetts Lowell

Amy Peterson ( $\nabla$ amy_peterson@uml.edu )

University of Massachusetts Lowell

\section{Research Article}

Keywords: polymer , tissue outcomes, half-lives, degradation model

Posted Date: December 7th, 2020

DOI: https://doi.org/10.21203/rs.3.rs-117440/v1

License: (c) (1) This work is licensed under a Creative Commons Attribution 4.0 International License.

Read Full License 


\title{
Half-Life Modeling of Basic Fibroblast Growth Factor and its Media Concentration from Growth Factor-Eluting Polyelectrolyte Multilayers
}

Ivan Ding a and Amy M. Peterson ${ }^{\mathrm{b}^{\mathrm{a}}}$

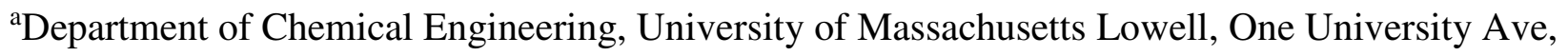
Lowell, MA 01854

${ }^{b}$ Department of Plastics Engineering, University of Massachusetts Lowell, One University Ave, Lowell, MA 01854

*Email: amy_peterson@uml.edu

\begin{abstract}
Growth factor-eluting polymer systems have been widely reported to improve cell and tissue outcomes; however, measurements of actual growth factor concentration in cell culture conditions are limited. The problem is compounded by a lack of knowledge of growth factor halflives, which impedes efforts to determine real-time growth factor concentrations. In this work, the half-life of basic fibroblast growth factor (FGF2) was determined using enzyme linked immunosorbent assay (ELISA). FGF2 release from polyelectrolyte multilayers (PEMs) was measured and the data was fit to a simple degradation model, allowing for the determination of FGF2 concentrations between 2 days and 4 days of culture time. After the first hour, the FGF2 concentration for PEMs assembled at $\mathrm{pH}=4$ ranged from $2.67 \mathrm{ng} / \mathrm{mL}$ to $5.76 \mathrm{ng} / \mathrm{mL}$, while for PEMs assembled at $\mathrm{pH}=5$, the concentration ranged from $0.62 \mathrm{ng} / \mathrm{mL}$ to $2.12 \mathrm{ng} / \mathrm{mL}$. CRL-2352 fibroblasts were cultured on PEMs assembled at $\mathrm{pH}=4$ and $\mathrm{pH}=5$. After 2 days, the FGF2-eluting PEM conditions showed improved cell count and spreading. After 4 days, only the $\mathrm{pH}=4$ assembly condition had higher cells counts, while the PEM assembled at $\mathrm{pH}=5$ and PEM with no FGF2
\end{abstract}


showed increased spreading. Overall, the half-life model and cell culture study provide optimal concentration ranges for fibroblast proliferation and a framework for understanding how temporal FGF2 concentration may affect other cell types.

\section{Introduction}

The controlled release of biologically relevant molecules is of great interest in the biomedical field, where exogenous methods of supplementation can be costly and risk contamination of products meant to directly treat patients. ${ }^{1}$ Polyelectrolytes have been employed as core components of many controlled-release systems due to their versatility. ${ }^{2}$ From the same starting materials, polyelectrolytes can form a number of different structures, including polyelectrolyte multilayer (PEM) coatings, polyelectrolyte complexes (PECs), complex coacervates, or microcapsules. ${ }^{3-12}$ The structure and properties of the resulting material depend on factors including the assembly method, polyelectrolyte concentrations, $\mathrm{pH}$, and temperature. ${ }^{3,13-15}$ For this reason, polyelectrolytes have been used for a range of cell scaffolds and surface coatings capable of releasing specific nanoparticles, pharmaceuticals, and proteins. ${ }^{7-11,16}$

PEMs specifically have been used extensively to control the release of growth factors (GFs) such as basic fibroblast growth factor (FGF2), bone morphogenetic protein (BMP-2), and transforming growth factor beta 1 (TGF- $\beta 1) . .^{3,6,17,18}$ FGF2 is especially important for the growth of both fibroblasts and mesenchymal stem cells and is linked to improved proliferation and decreased cell death rate, and can also prevent differentiation to undesirable phenotypes. ${ }^{3,19-23}$ PEMs are well-suited to the controlled release of GFs due to their ability to maintain GF bioactivity and release GFs over periods ranging from weeks to months. ${ }^{3,6,17}$ Furthermore, when PEMs without GFs are used alone to modify culture surface properties, they can improve cell proliferation 
compared to common culture substrates and implanted device materials such as tissue culture plastic (TCP) and titanium. ${ }^{3,6,17}$ The ability to simultaneously control surface properties and GF release rates, coupled with the ease of processing, make PEMs excellent materials for improving cell outcomes both in vitro and in vivo when paired with GFs.

While numerous publications report that GF-eluting PEMs greatly improve cell outcomes, many do not quantify the actual concentrations of GF released into the system. ${ }^{6,18,24,25}$ Methods for measuring GF concentration include enzyme-linked immunosorbent assay (ELISA), fluorescent labeling, and western blot. ${ }^{3-5,17,26-28}$ However, all of these methods have limitations. Fluorescent labeling requires modification of the starting protein, potentially changing the properties of or damaging the GF of interest. ${ }^{29}$ Western blot requires much higher concentrations than the 0.1-100 $\mathrm{ng} / \mathrm{mL}$ optimal dosage of GFs such as FGF2 and the number of conditions that can be characterized simultaneously is limited by gel and well sizes. ${ }^{19,30-32}$ ELISA may detect non-bioactive protein that possesses the necessary binding groups, and may not detect bioactive forms of the protein if they cannot bind with ELISA antibodies. ${ }^{33}$ For both methods, these limitations are compounded by the fact that GFs degrade over time under physiological conditions. At a specific time point, the concentration detected will inevitably be lower than the true amount released due to the loss of GF bioactivity. Despite the impact of protein degradation on measurement accuracy, there is almost no research on the half-lives of even the most common growth factors. In the literature, there are references to FGF2 half-life, but there is only one experimental investigation that quantifies the half-life value. Shiba et al. used western blot and estimated a half-life ranging from 4.7 to 13.7 hours depending on the presence of polyphosphate media supplements. ${ }^{30}$ Han et al. measured FGF2 degradation in phosphate buffered saline (PBS) using ELISA, but no further analysis of the half-life was performed in their work. ${ }^{11}$ Due to the differences in the methodology 
and concentration readings, generating an accurate model of FGF2 degradation using ELISAderived results necessitates determining its ELISA-detectable half-life.

In this work, we developed a working model of growth factor release from PEMs and subsequent degradation by obtaining an ELISA-detectable half-life of FGF2 and applying it to a new dataset. Half-life values were obtained by measuring concentrations of FGF2 dissolved in both PBS and Dulbecco's modified Eagle medium (DMEM) over a period of 4 days. PEMs consisting of poly-L-histidine (PLH) and poly(methacrylic acid) (PMAA) were prepared at a range of assembly $\mathrm{pH}$ values in order to obtain a new data set for GF release. Combining these results provided an ELISA-detectable concentration profile of FGF2 from the GF-eluting PEMs. The ability of the PEMs to improve cell proliferation and attachment was determined using CRL-2352 fibroblasts.

\section{Results \& Discussion}

\subsection{PEM Half Life}

The ELISA-detectable half-life for FGF2 was obtained to more accurately predict FGF2 concentrations. We specify "ELISA-detectable" to differentiate the values from other methods that may result in different readings. Figure 1 shows FGF2 concentration curves obtained over 4 days and the same data on a natural logarithmic scale. The initial time point taken 1 hour after plating shows a lower value than the expected starting concentration, likely due to a combination of a small amount of initial adsorption, including during mixing and transfer of aliquots to vials, and losses during freezing. Nonetheless, the results showed a gradual decrease in ELISA-detectable FGF2 concentration over the course of the 4-day study, resulting in an over 10-fold drop in concentration for all conditions. For PBS, the final concentrations were $7.07 \pm 0.96 \mathrm{ng} / \mathrm{mL}$ and 
$2.78 \pm 0.94 \mathrm{ng} / \mathrm{mL}$ for high and low initial concentrations, respectively. For DMEM, the final concentrations were $12.25 \pm 3.44 \mathrm{ng} / \mathrm{mL}$ and $6.13 \pm 1.85 \mathrm{ng} / \mathrm{mL}$ for high and low, respectively. Final FGF2 concentrations in DMEM were statistically significantly higher than PBS conditions $(\mathrm{p}>0.01)$.
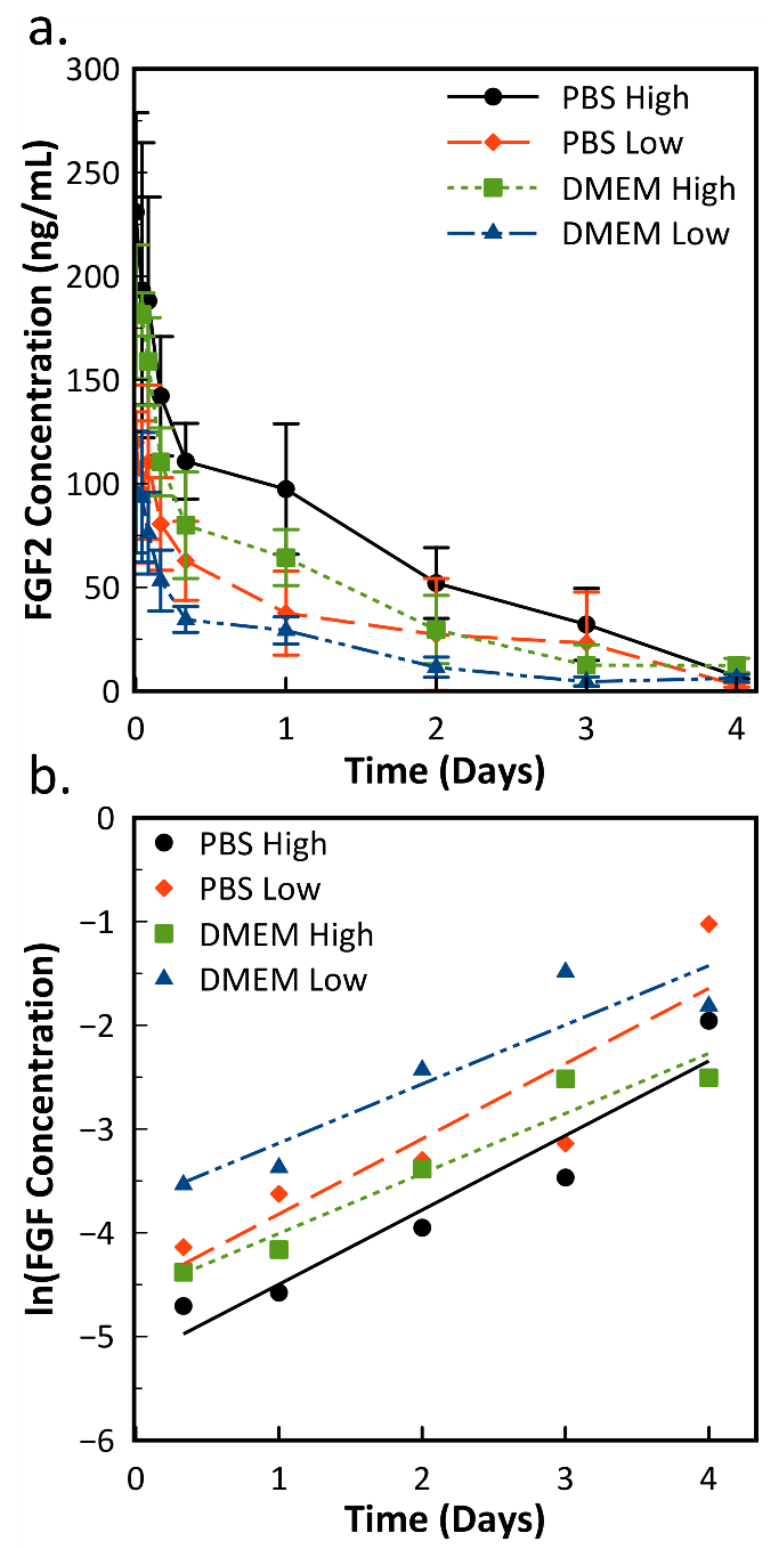

Figure 1. a. ELISA-detectable FGF2 at high $(500 \mathrm{ng} / \mathrm{mL})$ and low $(250 \mathrm{ng} / \mathrm{mL})$ initial starting concentrations in both PBS and unmodified DMEM over the course of 4 days. Error bars represent standard deviation $(n=5)$. b. Natural logarithm of the same average concentration values with a 
linear fit from $8 \mathrm{~h}$ to $96 \mathrm{~h}$. The fit line is used to determine the degradation constant to calculate the half-life.

Protein degradation has been studied using a two-state equilibrium model, where the protein in a native confirmation loses activity in an equilibrium reaction between folding/unfolding. ${ }^{34}$ This model is described by Equation 2.

$$
N \leftrightarrow U \rightarrow F
$$

$N$ is the native state of a protein, $U$ is the unfolded state, and $F$ is any state where the protein can no longer return to the native state in any manner. When the first reaction (folding/unfolding) reaches equilibrium, the overall reaction can be treated as pseudo-first order. Thus, the degradation rate can be described by Equation 3 .

$$
N(t)=N_{0}-k * t
$$

In Equation 3, $t$ is time, $N(t)$ is the FGF2 concentration at that time, $N_{0}$ is the original concentration, and $k$ is the first order rate constant describing the reaction of $U$ to $F$. By taking the natural logarithm of the experimental concentration vs. time data and applying a linear fit, the k value can be obtained from the slope of the line.

FGF2 concentration vs. time data does not fit first order kinetics for the first four hours. This is likely because the folding/unfolding reaction does not reach equilibrium during this time. The FGF2 used for these experiments was reconstituted from a lyophilized state, diluted, then heated to the experimental temperature, so it seems reasonable that equilibration would not be achieved immediately. The result is a fast degradation rate in the first few hours of the experiment.

To account for the non-equilibrium conditions during initial plating, only data from $8 \mathrm{~h}$ to $96 \mathrm{~h}$ was used in the calculation, as it more accurately describes long-term FGF2 degradation. 
Average half-life values were determined for each condition and are given in Table 1. No statistically significant differences were observed across experimental conditions. The lowest is 22.78 \pm 2.95 hours and the highest is $29.82 \pm 6.77$ hours. The results here indicate that FGF2 concentrations obtained in PBS-based release studies directly translate to conditions in cell culture. Likewise, the consistency of half-life values between two different initial FGF2 concentrations indicates that the reduction over time in ELISA-detectable FGF2 is real and not due to adsorption to the plate over the 4-day study. The half-life values in Table 1 are much higher than previously reported results by Shiba et al. using western blot, which range from 4.7 to 13.7 hours. ${ }^{30}$ The data in the current work agrees better with the activity loss studied via ELISA presented in Han et al. ${ }^{11}$ This difference in reported values is not necessarily due to the differences in western blot and ELISA, rather the reported western blot values are for a $24 \mathrm{hr}$ study, which would result in a lower half-life if the experiment was performed while in a non-equilibrium state.

Table 1. Calculated FGF2 half-life values taken from ELISA data. Half-life values were obtained from individual curves for each replicate.

\begin{tabular}{|l|l|l|l|}
\hline Condition & Half Life (hr) & Std. Dev. $($ hr $)$ & $\mathbf{R}^{\mathbf{2}}$ \\
\hline PBS $(500 \mathrm{ng} / \mathrm{mL})$ & 22.75 & 2.27 & 0.92 \\
\hline PBS $(250 \mathrm{ng} / \mathrm{mL})$ & 22.5 & 4.2 & 0.81 \\
\hline DMEM $(500 \mathrm{ng} / \mathrm{mL})$ & 27.95 & 3.11 & 0.94 \\
\hline DMEM $(250 \mathrm{ng} / \mathrm{mL})$ & 29.82 & 6.77 & 0.85 \\
\hline
\end{tabular}

\section{2 pH Dependence of PMAA/PLH PEMs}

In order to both explore the effects of assembly $\mathrm{pH}$ for PEMs on tissue culture plastic, and to obtain a data set for modeling purposes, a release study was performed on PEMs assembled at $\mathrm{pH}=4, \mathrm{pH}=5, \mathrm{pH}=6, \mathrm{pH}=7$, and $\mathrm{pH}=8$. Figure 2 shows the results of this study. Assembling the 
$\mathrm{PEM}$ at $\mathrm{pH}=4$ results in the highest $\mathrm{FGF} 2$ concentration after 7 days at $4.71 \pm 1.13 \mathrm{ng} / \mathrm{mL}$, which is statistically significantly higher than $\mathrm{PEMs}$ assembled at $\mathrm{pH}=5, \mathrm{pH}=7$, and $\mathrm{pH}=8(\mathrm{p}<0.05)$. FGF2 release from PEMs assembled at $\mathrm{pH}=5(2.3 \pm 0.44 \mathrm{ng} / \mathrm{mL})$ and above were not statistically significantly different.

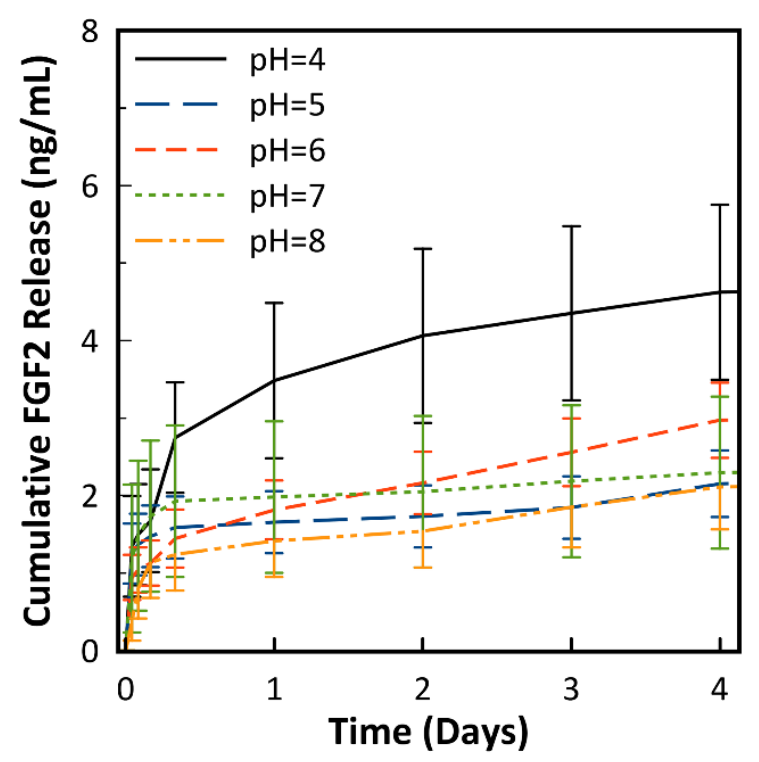

Figure 2. Cumulative FGF2 release over 4 days from FGF2-(PMAA/PLH) 5 PEMs. Error represents standard deviation $(\mathrm{n}=5)$.

Quartz crystal microbalance with dissipation monitoring (QCM-D) was performed to investigate how assembly $\mathrm{pH}$ affects PEM structure. The results are shown in Figure 3. From $\mathrm{pH}=4$ to $\mathrm{pH}=6$, the thickness of the PEM increased with increasing $\mathrm{pH}$. Likewise, the ratio of PLH to PMAA in each bilayer increased. This trend only holds true until $\mathrm{pH}=7$, where there is a sharp drop in PEM mass. PLH visibly begins to precipitate in the storage vial at $\mathrm{pH}=7$, forming what appears to be a complex coacervate, likely due to the mixture of positive and negative charges common for polyamino acids at neutral $\mathrm{pH}$ values. At $\mathrm{pH}=7$, the QCM-D results show that there is minimal adsorption of the PMAA layer and PEM formation is primarily driven by PLH. At 
$\mathrm{pH}=8$, the addition of PMAA results in rapid stripping followed by adsorption resulting in a mass slightly below or equal to the initial value. At $\mathrm{pH}=7$, the QCM-D results show that there is minimal adsorption of the PMAA layer and PEM formation is primarily driven by PLH. At $\mathrm{pH}=8$, the addition of PMAA results in rapid stripping followed by adsorption resulting in a mass slightly below or equal to the initial value.

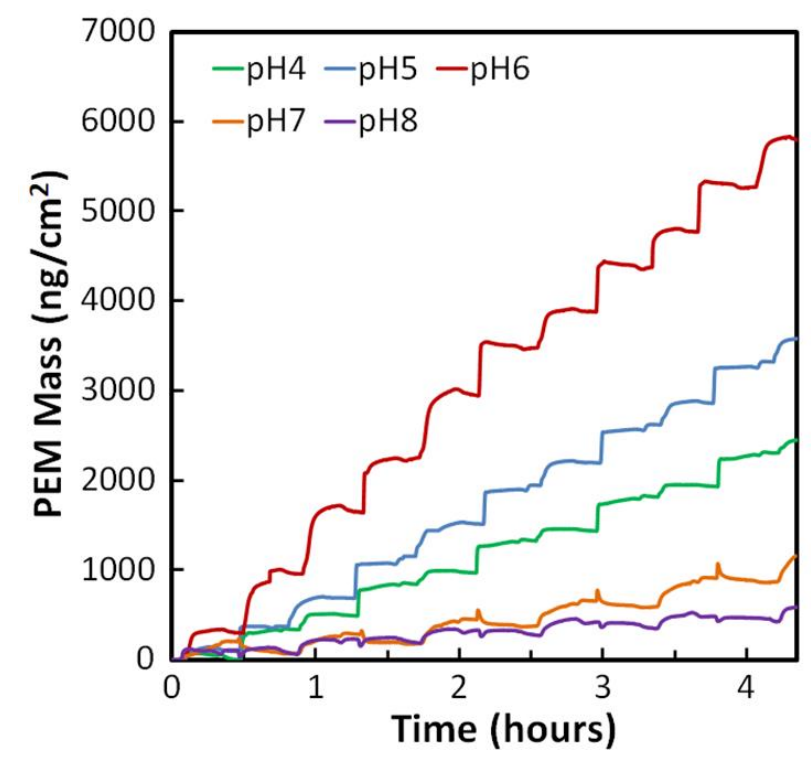

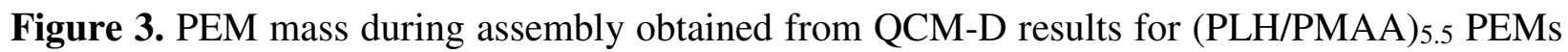
assembled at a $\mathrm{pH}$ range from $\mathrm{pH}=4$ to $\mathrm{pH}=8$.

From $\mathrm{pH}=4$ to $\mathrm{pH}=6$, PEMs grow superlinearly, indicated by the moderate increases in PEM mass per layer. Changes in PEM mass with assembly $\mathrm{pH}$ are expected for weak polyelectrolytes such as the ones used in this work. Similar results have been seen in the literature for poly(acrylic acid)/poly(allylamine hydrochloride) PEMs, albeit in a much smaller $\mathrm{pH}$ range. ${ }^{35}$ For PMAA/PLH PEMs, it is likely that the range between $\mathrm{pH}=5$ and $\mathrm{pH}=6$ are where the polyelectrolytes have the highest charge density, resulting in a driving force favoring adsorption. At even the very first layer, we see increased PLH adsorption, which is then balanced by a greater 
mass of PMAA adsorbed in the second layer. This is repeated throughout the adsorption process, resulting in a doubled mass when comparing the $\mathrm{pH}=6$ PEM to the $\mathrm{pH}=4 \mathrm{PEM}$.

Similarly, the collapse of PEM mass in the intermediate $\mathrm{pH}$ range occurs as the ionization of both individual polyelectrolytes decreases. ${ }^{35}$ For the PMAA/PLH polyelectrolyte, this leads to instability in the PEM resulting in stripping. During PEM assembly, adsorption and stripping directly compete. ${ }^{36}$ On an individual layer level, it can be seen that when PMAA is introduced at $\mathrm{pH}=7$ and $\mathrm{pH}=8$, stripping overtakes adsorption, resulting in loss of polyelectrolyte mass before more is adsorbed in that same layer. As PEMs are dynamic, rearrange during formation, and do not typically form discrete layers, loss in mass likely correlates to a simultaneous loss in FGF2.

By comparing the QCM-D results to the FGF2 release curves, some conclusions can be drawn. Thin and unstable PMAA/PLH PEMs release lower amounts of FGF2 due to stripping of portions of the PEM mass during adsorption. This can be seen clearly from the $\mathrm{pH}=7$ and $\mathrm{pH}=8$ conditions. Increasing PEM mass is correlated to lower FGF2 release, but may not be the cause. A likely explanation is that the PEMs at $\mathrm{pH}=5$ and $\mathrm{pH}=6$ conditions are less able to maintain FGF2 bioactivity compared to the $\mathrm{pH}=4$ condition. Differences in chain arrangement, charge, and moisture uptake at the higher $\mathrm{pH}$ values can all result in decreased FGF2 bioactivity.

Comparing the remaining amount of FGF2 adsorbed to the substrate after the release study provides further insight on the differences of the different $\mathrm{pH}$ conditions. Remaining FGF2 surface concentrations were not statistically significantly different for the $\mathrm{pH}=4, \mathrm{pH}=5$, and $\mathrm{pH}=6$ samples $\left(6.7 \pm 2.31 \mathrm{ng} / \mathrm{cm}^{2}, 6.6 \pm 2.95 \mathrm{ng} / \mathrm{cm}^{2}, 4.2 \pm 0.51 \mathrm{ng} / \mathrm{cm}^{2}\right.$ respectively). However, the amount of remaining $\mathrm{FGF} 2$ for the $\mathrm{pH}=7$ and $\mathrm{pH}=8$ conditions are lower, at $3.1 \pm 1.30 \mathrm{ng} / \mathrm{cm}^{2}$ and $0.6 \pm 0.22$ $\mathrm{ng} / \mathrm{cm}^{2}$, respectively. This reinforces the idea that less FGF2 was adsorbed in the $\mathrm{pH}=7$ and $\mathrm{pH}=8$ PEMs, but not at the lower assembly $\mathrm{pH}$ values. However, as the amounts of FGF2 released were 
statistically similar throughout the $\mathrm{pH}=5$ to $\mathrm{pH}=8$ range, it is clear that the release kinetics and arrangement of the polyelectrolyte chains within the PEM differ for each assembly $\mathrm{pH}$ condition.

PEM stability is likely the greatest contributing factor to the GF release results. Previous work on titanium-coated substrates showed that mass loss when exposed to PBS was minimized for a PEM formed at $\mathrm{pH}=4$, compared to those formed at $\mathrm{pH}$ values closer to that of PBS $(\mathrm{pH}=7.4) .{ }^{17}$ In this system, polyelectrolyte choice plays an important role and the most stable PMAA/PLH PEM forms at $\mathrm{pH}=4$ where the positive charge of the polyamino acid, PLH, is greatest among the tested conditions. This increased stability results is a coating that is most able to maintain and release ELISA-detectable FGF2.

\subsection{Concentration Modeling}

A model of FGF2 solution concentration was developed by applying the ELISA-detectable FGF2 half-life value to the release study data. The model was generated iteratively in MATLAB, employing two simultaneous equations accounting for first order degradation (Equation 3) and growth factor release in the form of the Power Law model (Equation 4). ${ }^{37}$

$$
\frac{M_{t}}{M_{\infty}}=k t^{n}
$$

$M_{t}$ is the cumulative release up to a specific time $t, M_{\infty}$ is the total amount of drug released after an infinite time period, $K$ is a constant representing geometric factors of the release systems, and $n$ is a constant representing the mode of release. $M_{\infty}$ was taken as the cumulative release plus the recovered FGF2 from an acid-base wash. Compared to other drug release models such as the Higuchi Equation, the fit parameters in the Power Law model more accurately describe initial swelling behavior on contact with a solvent, as seen in PEM systems. ${ }^{37}$ 
Before fitting the experimental release data to the power law, the numerical values were adjusted using the experimentally obtained half-life value in order to account for degradation that occurs during the release studies themselves. The chosen half-life value was 22.75 hours, which was taken from the higher concentration PBS data from Table 1 due to its lower relative standard deviation. After the adjusted release curve was obtained, Equation 3 and Equation 4 could be solved numerically. Figure 4a shows this methodology applied to the data obtained at the tested $\mathrm{pH}$ values compared to exogenous FGF2 supplementation. Graphs of specific curves to reach the final modeled release can be seen in the Supporting Information. The exogenous supplementation data seen in Figure 4b was obtained by applying Equation 3 by itself. 

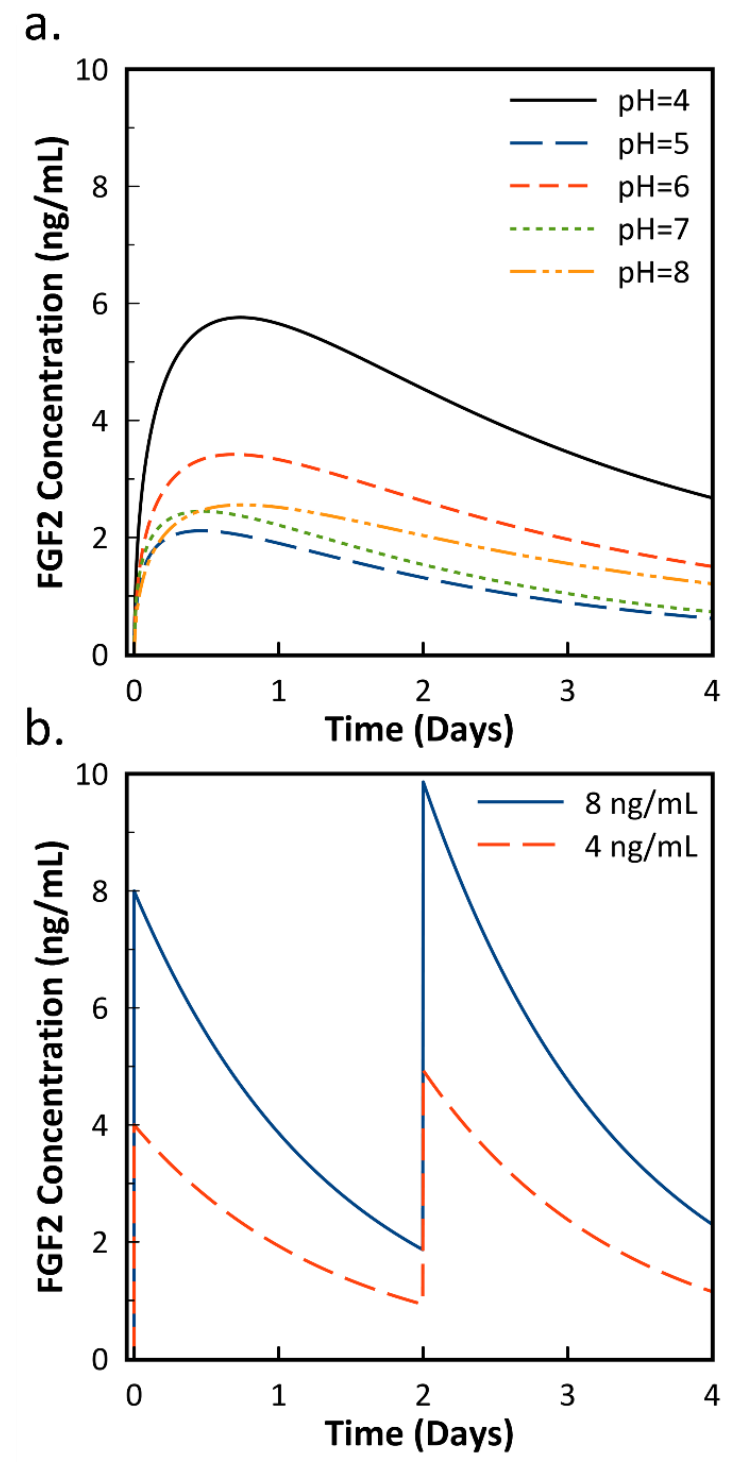

Figure 4. a. Modeled concentration of FGF2 released from PEMs. pH values refer to PEM assembly conditions. Model assumes a $1.9 \mathrm{~cm}^{2}$ surface area and $600 \mu \mathrm{L}$ of media. b. Modeled FGF2 concentrations assuming exogenous supplementation of FGF2 at $4 \mathrm{ng} / \mathrm{mL}$, and $8 \mathrm{ng} / \mathrm{mL}$, at both $\mathrm{t}=0$ and $\mathrm{t}=2$ days.

FGF2 concentrations generally follow the trends seen in the release study, with the highest cumulative release resulting in the highest FGF2 concentration over time. FGF2 concentrations increase rapidly over the course of the first day, but gradually decline over the next 3 days. Figure 
4b shows the FGF2 concentration curve for an exogenous condition where FGF2 is supplemented initially and after 2 days without total media replacement. For the exogenous condition to have the same amount of FGF2 after 4 days as the $\mathrm{pH}=4$ condition, a concentration between $8-16 \mathrm{ng} / \mathrm{mL}$ of FGF2 would be required. Table 2 shows the modeled FGF2 concentrations after 2 days and 4 days. When $16 \mathrm{ng} / \mathrm{mL}$ of exogenous FGF2 is added both initially and after 2 days, the FGF2 concentration range reaches as low as $3.71 \mathrm{ng} / \mathrm{mL}$ before supplementation and as high as 19.71 $\mathrm{ng} / \mathrm{mL}$ after supplementation. For $8 \mathrm{ng} / \mathrm{mL}$, the concentration decreases as low as $1.86 \mathrm{ng} / \mathrm{mL}$. In order to maintain FGF2 concentrations through exogenous means, a more rigorous supplementation cycle is required, resulting in more physical interaction with the culture system, risking contamination. These results demonstrate a major benefit of GF-eluting PEMs compared to traditional methods.

Table 2. Modeled growth factor concentrations after 2 days and 4 days of culture time. For the exogenous FGF2 conditions, values were taken before additional FGF2 was supplemented.

\begin{tabular}{|c|c|c|c|c|c|c|c|c|}
\hline \multicolumn{4}{|c|}{ PEM } & \multicolumn{5}{|c|}{ Exogenous FGF2 } \\
\hline & $\mathrm{pH}=4$ & $\mathrm{pH}=5$ & $\mathrm{pH}=6$ & $\mathrm{pH}=7$ & $\mathrm{pH}=8$ & $16 \mathrm{ng} / \mathrm{mL}$ & $8 \mathrm{ng} / \mathrm{mL}$ & $4 \mathrm{ng} / \mathrm{mL}$ \\
\hline & 4.53 & 1.31 & 2.61 & 1.53 & 2.03 & 3.72 & 1.86 & 0.93 \\
\hline Jav & 2.67 & 0.62 & 1.49 & 0.73 & 1.20 & 4.58 & 2.28 & 1.14 \\
\hline
\end{tabular}

Application of the short-term western blot-based values for FGF2 half-life, which range from 4.7 to 13.7 hours, results in underestimation of FGF2 concentrations in the media. ${ }^{3,30}$ Based on the presented model, it is clear that FGF-eluting PEMs are more able to maintain FGF2 concentrations within specific ranges over the course of several days. 


\subsection{Cell Culture}

A cell culture study was performed with CRL-2352 fibroblasts to determine the performance of the GF-eluting PEM compared to exogenous FGF2 supplementation. This cell line was chosen because it is highly proliferative in the presence of FGF2. ${ }^{3,38,39}$ Based on the release profiles obtained from the model, high and low FGF2-eluting PEM conditions $(\mathrm{pH}=4$ and $\mathrm{pH}=5$ respectively) were chosen as experimental conditions. Two exogenous conditions where $4 \mathrm{ng} / \mathrm{mL}$ and $8 \mathrm{ng} / \mathrm{mL}$ of FGF2 were added at $\mathrm{t}=0$ days and $\mathrm{t}=2$ days were chosen to bracket the lower and upper concentration ranges of the FGF2-eluting PEMs. The exogenous conditions had a PEM coating with no initial adsorbed FGF2 layer to act as a direct comparison to FGF- eluting surfaces. PEM-only and uncoated surfaces served as controls.

Figure 5 shows representative fluorescence images of cells labeled with Hoechst 33342 (blue) and phalloidin (green). At 2 days, the cells are morphologically similar across culture conditions. The actin cytoskeleton shows the cells are elongated in all conditions, indicative of a fibroblastic character. ${ }^{39}$ 
a.

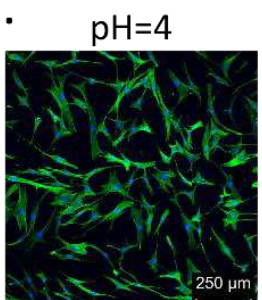

$\mathrm{pH}=5$

8-ng
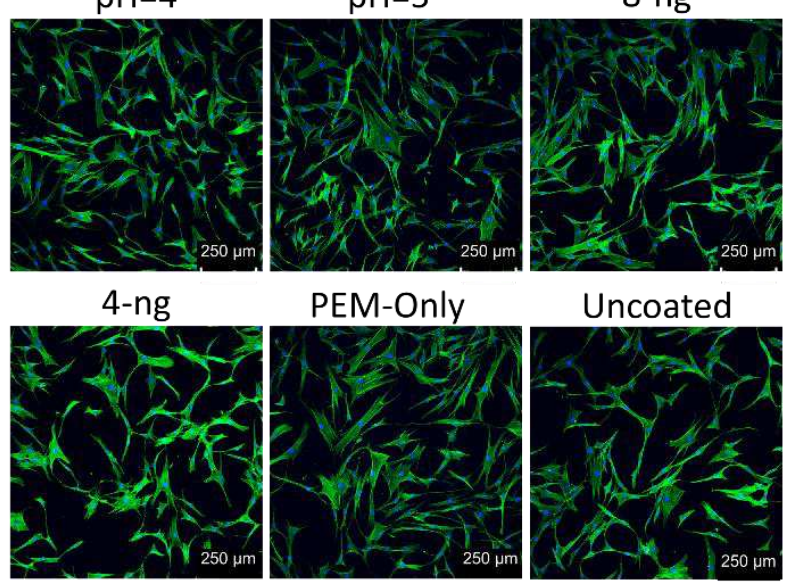

PEM-Only

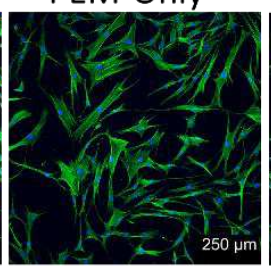

Uncoated

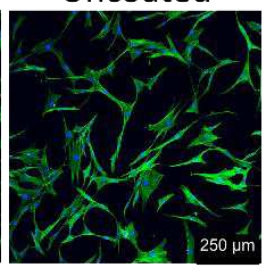

b.

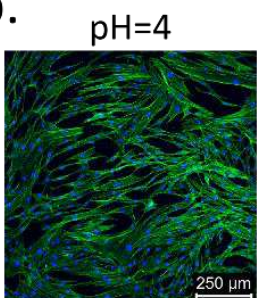

$\mathrm{pH}=5$

8-ng
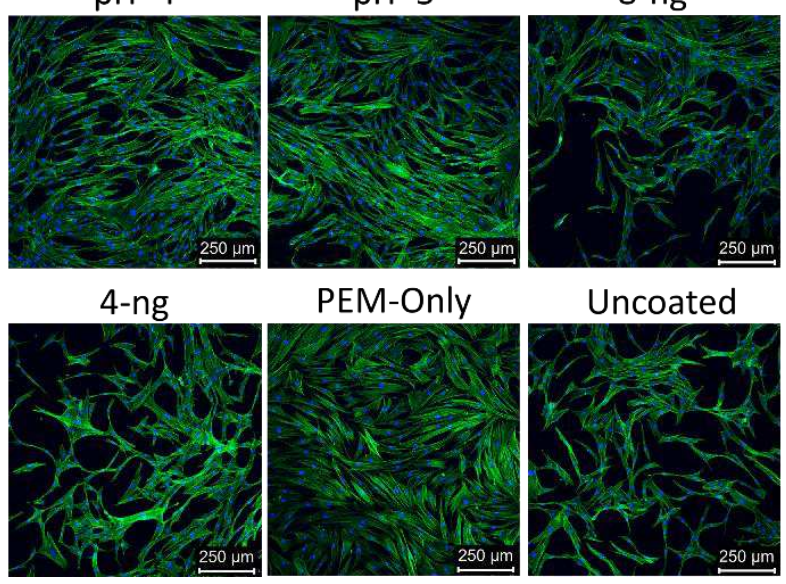

PEM-Only

Uncoated
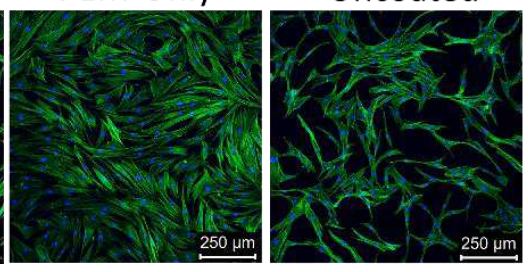

Figure 5. Representative images of cells stained with Hoechst 33342 (blue) and phalloidin coupled with Alexa Fluor 488 (green) at a. 2 days and b. 4 days of culture time. pH values refer to PEM assembly conditions.

Figure 6a shows cell counts at the two time points. At 2 days, cell counts for $\mathrm{pH}=4$ and $\mathrm{pH}=5$ are $10,278 \pm 1,857$ cells $/ \mathrm{cm}^{2}$ and $9,387 \pm 1,785$ cells $/ \mathrm{cm}^{2}$, respectively. These are statistically significantly higher than the other conditions, which are comparable to the uncoated control at $8,056 \pm 1,322$ cells $/ \mathrm{cm}^{2}$. The cell counts are close to the seeding density, indicating that not all cells attached initially in low serum conditions. Figure $6 \mathrm{~b}$ shows the average cell surface area. At 2 days, the $\mathrm{pH}=4\left(5,905 \pm 1,568 \mu \mathrm{m}^{2}\right)$ and $\mathrm{pH}=5\left(6,094 \pm 1,192 \mu \mathrm{m}^{2}\right)$ FGF2-eluting PEMs had higher 
average cell surface areas than all other conditions. The 8-ng condition $\left(5,052 \pm 789 \mu \mathrm{m}^{2}\right)$ and PEMonly condition $\left(4,829 \pm 594 \mu \mathrm{m}^{2}\right)$ have higher cell surface areas than the uncoated control $\left(3,414 \pm 296 \mu \mathrm{m}^{2}\right)$. This indicates that the PEM coating by itself increases cell attachment and spreading after two days of culture time. However, only the FGF2-eluting PEM conditions resulted in increased cell counts at 2 days.
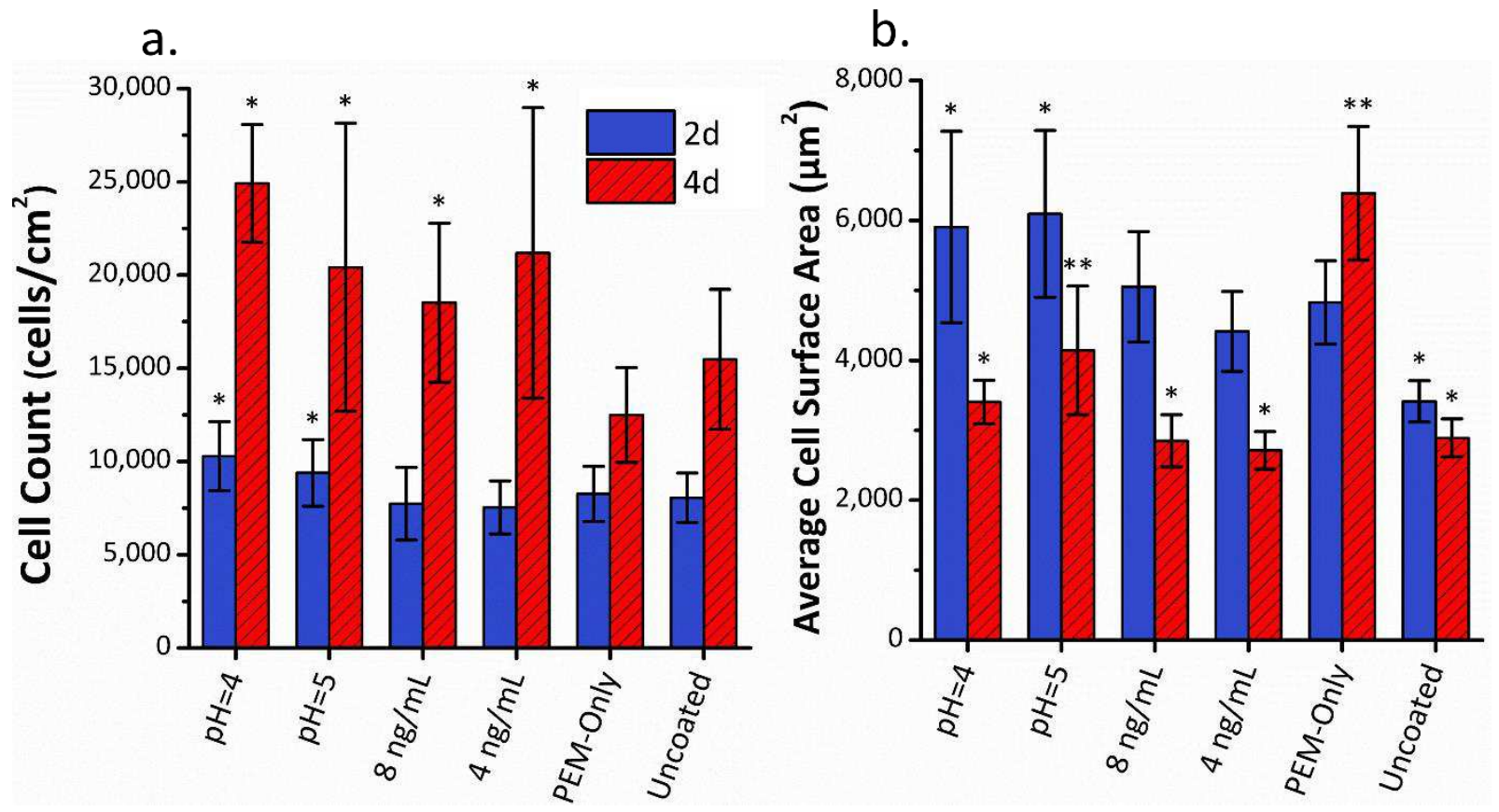

Figure 6. Comparison between 2-day and 4-day results for a. cell counts obtained from Hoechst 33342 nuclear staining and b. average cell surface areas from phalloidin labeling. Error bars represent standard deviation $(\mathrm{n}=12) . *$ represents statistical differences from PEM-only control of the same time point. ** represent statistical differences from all other conditions at the same time point.

The results at 4 days do not follow the trends seen at 2 days. At 4 days, all FGF2-positive conditions show statistically significant increases to cell count compared to the PEM-only and uncoated controls. This is reasonable, as proliferation signaling is a primary function of FGF2. ${ }^{39,40}$ 
Furthermore, the FGF2-eluting PEM at $\mathrm{pH}=4$ has a statistically significantly higher cell count than the 8 ng exogenous condition, indicating that the FGF2-eluting PEM may be superior to exogenous delivery at certain concentrations. However, for both GF-eluting PEMs and exogenous FGF2, control of concentration is extremely important.

Interestingly, the order of relative cell sizes differs greatly at 4 days compared to 2 days. At 4 days, the largest cells are found in the PEM-only condition, followed by $\mathrm{pH}=5$, then all other conditions. The PEM-only condition has a similar cell count to the uncoated control, but almost double the cell size. In part, the decreased cell spreading in the FGF2-positive conditions may be due to higher cell densities resulting in contact inhibition. However, this is likely a very small contributing factor. CRL-2352 fibroblasts do not purely form monolayers, and only reach $100 \%$ confluence at 40,000 cells $/ \mathrm{cm}^{2}$. Furthermore, the $\mathrm{pH}=4$ condition has similar cell sizes to the 8 $\mathrm{ng} / \mathrm{mL}$ condition despite differences in cell count. The fact that the cell size is second largest in the $\mathrm{pH}=5$ condition, the condition with the lowest FGF2 concentration, indicates that the PEM and FGF2 have competing effects on cell size. Based on the model, FGF2 concentrations in the $\mathrm{pH}=5$ condition remains below $2 \mathrm{ng} / \mathrm{mL}$ after the first day of culture and drops to as low as $0.62 \mathrm{ng} / \mathrm{mL}$ after 4 days. While the 4-ng exogenous condition reaches as low as $0.93 \mathrm{ng} / \mathrm{mL}$ at 2 days, there is a spike in concentration after supplementation at that time point. A sufficient FGF2 concentration likely reduces cell size due to the ability of FGF2 to maintain a more fibroblastic character, despite changes in morphology than can be induced by the PEM coating.

Both concentration and method of FGF2 presentation likely play a role in the proliferation results. When comparing the FGF2-eluting and exogenous conditions as a whole, FGF2 adsorbed into the PEM either improves cell adhesion or is more readily available to the cell upon initial attachment, causing an increased cell count at the 2-day mark. However, a specific concentration 
range may be necessary to optimize cell proliferation. Lower cell counts in the $8 \mathrm{ng} / \mathrm{mL}$ condition suggest that the FGF2 concentration is too high, reducing its effectiveness. On the other end of the spectrum, the FGF2 concentration achieved by the $\mathrm{pH}=5 \mathrm{PEM}$ is insufficient to achieve maximum cell proliferation. From 2 days to 4 days, the $\mathrm{pH}=5$ condition underwent 2.18 population doublings, compared to the 2.4-2.8 population doublings seen in the other FGF2-containing conditions. As the $\mathrm{pH}=5$ condition has the lowest maximum FGF2 concentration at $2.11 \mathrm{ng} / \mathrm{mL}$, which decreases to as low as $0.62 \mathrm{ng} / \mathrm{mL}$ at 4 days, there may simply be an insufficient amount of FGF2 in the system after the 2-day time point. Based on these results, optimal FGF2 concentration is in the range of $2.11-9.86 \mathrm{ng} / \mathrm{mL}$.

Data for the cell surface areas are harder to interpret as the PEM and FGF2 simultaneously affect attachment. For the 2-day results, it is clear that FGF2-eluting PEMs improve either growth or initial attachment during seeding. This is likely due to the cells interacting with the FGF2 directly bound onto the surface. The PEM alone does not show this effect, nor does the PEM combined with exogenous FGF2. For that reason, we can conclude that presentation of FGF2 through direct contact with the PEM improves the viable number of cells during early culture over either material alone.

Care must be taken in modifying substrate properties - while improved fibroblast spreading is correlated with improved attachment, it may also be indicative of a more myofibroblastic, chondrogenic, or osteoblastic character. ${ }^{39,41}$ However, this concern can be addressed by supplementing FGF2 exogenously, or releasing it over time when culturing cells on a PEM. FGF2 is known to allow fibroblasts to more effectively maintain their phenotype. Ideally, the PEM improves attachment by increasing the surface charge, while the FGF2 prevents undesired differentiation and improves proliferation. This could have significant implications for cell 
expansion in bioreactor systems, as the shear forces risk the causing detachment or undesired differentiation of cells. ${ }^{28,42}$

From a proliferation standpoint, the (PMAA/PLH) 5 PEM and uncoated polystyrene have statistically similar cell counts, which is consistent with our previous results. ${ }^{3}$ However, confocal imaging and staining highlight that the extent of cell spreading is affected by the presence of a PEM. While exogenous addition of FGF2 to media is known to improve fibroblast proliferation, ${ }^{3,39,40}$ this work provides a better understanding of the optimal concentration ranges under which FGF2 should be supplemented. Furthermore, FGF2-eluting PEMs can increase fibroblast growth rates, likely due to improvements in early attachment and growth.

\section{Conclusions}

In this work, an ELISA-detectable half-life value was obtained for FGF2. This half-life was then used to model actual FGF2 concentrations in cell culture systems. The effects of assembly pH on FGF2 release was studied and serves as a representative system for the developed model. The highest FGF2 release rate was seen from PEMs assembled at $\mathrm{pH}=4$, while PEMs assembled at $\mathrm{pH}=5$ to $\mathrm{pH}=8$ showed approximately equal FGF2 release rates. Based on QCM-D results, the differences in release profile can be attributed to the ability of the PEM at this $\mathrm{pH}$ to better maintain growth factor bioactivity, and not related to PEM mass directly. The model showed that the $\mathrm{pH}=4$

condition could maintain FGF2 concentrations between $2 \mathrm{ng} / \mathrm{mL}$ and $6 \mathrm{ng} / \mathrm{mL}$ after 8 hours of culture time in a cell culture system with a $1.9 \mathrm{~cm}^{2}$ surface area and $600 \mu \mathrm{L}$ of cell culture media. The $\mathrm{PEM}$ assembled at $\mathrm{pH}=5$ could maintain a concentration between $0.5 \mathrm{ng} / \mathrm{mL}$ and $2.5 \mathrm{ng} / \mathrm{mL}$.

Fibroblasts were cultured at these same conditions to determine the effects of the FGF2eluting PEMs on cell attachment and proliferation. After 2 days, the FGF2-eluting PEMs had 
increased cell counts and spreading compared to exogenous FGF2 supplementation and the FGF2free controls. At 4 days, the cell count in the FGF2-eluting PEM assembled at pH=4 was higher than both the $8 \mathrm{ng} / \mathrm{mL}$ exogenous condition and the controls. Cell spreading was highest in the PEM-only control followed by the FGF2-eluting PEM assembled at $\mathrm{pH}=5$, indicating that the PEM and FGF2 may have a synergistic effect on cell attachment and proliferation.

These results show that FGF2 introduced from a GF-eluting PEM is capable of moderately increasing the number of viable cells early during culture. It has been established that presentation of other GFs from the surface directly can provide more bioavailable GF. This work is an early sign that this also applies to FGF2 released from a PEM. However, the observed benefits are limited to the first 2 days of cell culture. Exogenous FGF2 and FGF2-eluting PEMs have an approximately equal number of population doublings between the 2-day and 4-day time points. In addition to the benefits during early culture time, usage of an FGF2-eluting PEM eliminates the need for multiple FGF2 supplementation steps, reducing human intervention and the associated risk of contamination and variability. The presence of a PEM improves cell spreading and attachment, which is important for higher shear environments such as bioreactors. Altogether, FGF2 eluting PEMs provide practical improvements to traditional cell culture techniques and substrates.

\section{Methods}

\subsection{Materials}

Plasma-treated polystyrene petri dishes were purchased from Corning. Poly(methacrylic acid) sodium salt (PMAA, 30 wt.\% solution, MW 4000-6000), poly-L-histidine hydrochloride

(PLH, mol wt. $\geq 5000)$, PBS tablets ( $\mathrm{pH}=7.4)$, hydrochloric acid $(12.1 \mathrm{M})$, and 
tris(hydroxymethyl)aminomethane were obtained from Sigma-Aldrich. Sodium hydroxide (10N) and reagent grade ethyl alcohol was obtained from Fisher Scientific.

CRL-2352 fibroblasts were obtained from the American Type Culture Collection (ATCC). Gibco Iscove's Modified Dulbecco's Medium (IMDM) solution and Gibco fetal bovine serum (FBS) were obtained from Life Technologies Corporation. P/enicillin streptomycin, $0.25 \% / 2 \mathrm{mM}$ trypsin-EDTA, Dulbecco's Phosphate Buffered Saline (DPBS) and Alexa Fluor 488-coupled phalloidin were obtained from Thermo Fisher Scientific.

\subsection{FGF2 Half-Life Determination}

FGF2's half-life was determined in both PBS and DMEM to understand its degradation in a simulated cell culture environment. No additives such as fetal bovine serum were included, as they vary in concentration depending on the culture system. Before the study, 5 wells in a 6-well polystyrene cell culture plate were blocked with $2 \%$ BSA overnight at $37{ }^{\circ} \mathrm{C}$ to limit FGF2 adsorption during the experiment. After blocking, the plates were washed with $37{ }^{\circ} \mathrm{C}$ PBS twice after which $4 \mathrm{~mL}$ of PBS or DMEM with the appropriate FGF2 concentration were added to the wells. At the appropriate time point, a $100 \mu \mathrm{L}$ aliquot was taken from each of the wells without replacement and stored frozen until the ELISA study. The first time point was after a 1-hour incubation period at $37^{\circ} \mathrm{C}$ to limit the effects of adsorption to the well walls on the results. To account for non-equilibrium conditions, half-life results were obtained by fitting the data from 8 hrs to $96 \mathrm{hrs}$ to a first order rate law.

\subsection{Substrate Preparation and PEM Coating.}


Polyelectrolytes were prepared at a concentration of $1 \mathrm{mg} / \mathrm{mL}$ and Tris buffer was prepared at $0.05 \mathrm{M}$. Solution $\mathrm{pH}$ values were adjusted using $1 \mathrm{M} \mathrm{HCl}$ and $1 \mathrm{M} \mathrm{NaOH}$. Before coating, the substrates were cut into $1 \mathrm{~cm}^{2}$ squares and cleaned with deionized water, ethanol, and deionized water again. Following the cleaning, $50 \mu \mathrm{g} / \mathrm{mL}$ FGF2 in $\mathrm{pH}=7.6$ Tris buffer was pipetted onto one side of the substrate and allowed to adsorb for 15 minutes, followed by three washes in deionized water for 1 minute each. Using a dip coater (6 Position Compact SILAR Coating System, MTI), the substrates were immersed into $1 \mathrm{mg} / \mathrm{mL}$ PMAA for 15 minutes at the appropriate $\mathrm{pH}$ followed by two 90 -second wash steps with water at the same $\mathrm{pH}$. Another 15-minute adsorption step was performed for $1 \mathrm{mg} / \mathrm{mL}$ PLH, followed by two more wash steps. These two steps were repeated five times to form 5 bilayers, resulting in a FGF2-(PMAA/PLH) $)_{5}$ PEM. The samples were dried using compressed nitrogen gas and stored at $4{ }^{\circ} \mathrm{C}$ overnight.

\subsection{FGF2 Release Study}

To determine FGF2 release rates, the coated substrates were immersed in $1 \mathrm{~mL}$ of PBS in individual scintillation vials and incubated at $37{ }^{\circ} \mathrm{C}$. At the specified time points, PBS was collected and stored frozen at $-30{ }^{\circ} \mathrm{C}$ and $1 \mathrm{~mL}$ of fresh PBS was added to the vial. After collecting the aliquots at the 7-day time point, substrates were rinsed for 30 seconds in $0.5 \mathrm{~mL}$ of $0.1 \mathrm{M} \mathrm{HCl}$ followed by a second rinse with $0.5 \mathrm{~mL}$ of $0.1 \mathrm{M} \mathrm{NaOH}$. The $\mathrm{HCl}$ and $\mathrm{NaOH}$ aliquots were combined, $\mathrm{pH}$ adjusted to $\mathrm{pH}=7.4$ and stored at $-30{ }^{\circ} \mathrm{C} .4$

ABTS sandwich ELISA kits (PeproTech) were used to quantify FGF2 release and ELISA was performed in accordance to supplier instructions. Aliquots from the release studies were thawed and returned to room temperature immediately prior to their use. Absorbance readings of 
the developed ELISA plates were obtained using a Molecular Devices SpectraMax M2 plate reader at a reading wavelength of $405 \mathrm{~nm}$ with a reference wavelength of $650 \mathrm{~nm}$.

\subsection{Quartz Crystal Microbalance with Dissipation Monitoring}

QCM-D was used to monitor PEM assembly at different $\mathrm{pH}$ values using a Q-Sense E4 (Biolin Scientific) system with polystyrene-coated sensors to mimic the experimental substrate. 1 $\mathrm{mg} / \mathrm{mL}$ polyelectrolyte solutions were fed at a $50 \mu \mathrm{L} / \mathrm{min}$ flow rate for each layer followed by a 10-minute wash step using water of the appropriate $\mathrm{pH}$. An initial PLH first layer was used in place of FGF2 as both are positively charged below $\mathrm{pH}=7$. Frequency and dissipation were obtained at odd overtones from the 3rd to 13 th representing the harmonic resonances of the quartz crystal. The 3rd overtone was chosen to calculate the PEM mass as it best represents the bulk character of the film. ${ }^{43}$ The Sauerbrey equation for rigid films was used to determine the mass of the assembled PEM based on the raw frequency data (Equation 1):

$$
\Delta m=\frac{-C}{n \Delta f}
$$

where $m$ is the calculated adsorbed mass, $f$ is the resonant frequency, $n$ is the overtone number, and $C$ is the sensitivity constant, which is $17.7 \mathrm{ng} /\left(\mathrm{cm}^{2} \mathrm{~Hz}\right)$ for these $5 \mathrm{MHz}$ QCM-D sensors. Use of the Sauerbrey equation is appropriate if the films are rigid, characterized by a stable ratio of dissipation change to frequency change between overtones and is generally applicable for any PEM system under $40 \mathrm{~nm}$ in thickness. ${ }^{44}$

\subsection{Cell Culture}

Individual 4-well plates were coated manually under the same assembly conditions as described above. In place of dip coating, the solutions were deposited using a multi-pipettor and 
were aspirated after the appropriate time interval. $200 \mu \mathrm{L}$ of $50 \mu \mathrm{g} / \mathrm{mL}$ FGF2 was pipetted to the bottom of the well, followed by $300 \mu \mathrm{L}$ of DI water, then by $300 \mu \mathrm{L}$ of polyelectrolyte solution and $\mathrm{pH}$-adjusted wash water for each step, forming the full PEM. GF-eluting PEMs were prepared at $\mathrm{pH}=4$ and $\mathrm{pH}=5$. A PEM-only condition and uncoated surfaces were used as negative controls. Two conditions with $8 \mathrm{ng}$ and $4 \mathrm{ng}$ of exogenous FGF2 added at $\mathrm{t}=0$ days and $\mathrm{t}=2$ days were used as positive controls. The exogenous conditions had a PEM-only coating to serve as a direct comparison to the FGF2-eluting surfaces. The coated plates were sterilized under UV light for 10 minutes before starting culture.

Fibroblasts were initially expanded in complete growth medium (IMDM containing 10\% FBS, $1 \%$ L-glutamate, and $1 \%$ penicillin streptomycin). Cells at passage 4 were seeded at a density of 5,000 cells $/ \mathrm{cm}^{2}(9,500 \mathrm{cells} /$ well $)$ in individual 4-well plates for each condition and cultured in $600 \mu \mathrm{L}$ of IMDM containing $1 \% \mathrm{FBS}$ for 2 and 4 days at $37^{\circ} \mathrm{C}$ and $5 \% \mathrm{CO} 2$. At the specified time points, the 4-well plates were removed from the incubator. The media was aspirated and the cells were washed twice using $1 \mathrm{X}$ PBS with $\mathrm{Mg}^{2+}$ and $\mathrm{Ca}^{2+}$. The cells were fixed in $200 \mu \mathrm{L}$ of $4 \%$ paraformaldehyde in PBS for 10 minutes, after which two more rinses in PBS were performed. The fixed cells were stored at $8{ }^{\circ} \mathrm{C}$ until staining.

To permeabilize the cells, $0.1 \%$ Triton X-100 in PBS was added to the culture wells for 5 minutes followed by two washes in PBS again. Cells were incubated in a $1 \mathrm{wt} . \%$ BSA solution in PBS for 30 minutes to prevent non-specific binding of the fluorescent stains. After blocking, the wash step was repeated. The cell nuclei were stained using $300 \mu \mathrm{L}$ of Hoechst solution diluted 1:3,000 in PBS for 10 minutes under a foil cover. Phalloidin coupled with Alexa Fluor 488 was diluted to 2.5 vol.\% before staining. $300 \mu \mathrm{L}$ of solution was added per well and the stain was developed for 20 minutes under foil followed by two final washes with PBS. 
The cells were imaged using a Leica SP8 Confocal Microscope. Cell counts based on the nuclei count and surface area values were obtained using ImageJ. ${ }^{45}$

\subsection{Statistical Analysis}

Statistical analysis was performed using a single factor analysis of variance (ANOVA) for all experiments. The Tukey Honest Significant Difference (HSD) method was used for post hoc analysis and was applied simultaneously for all conditions at their respective time points in an experimental data set.

\section{References}

1. Tiwari, G. et al. Drug delivery systems: An updated review. Int. J. Pharm. Investig. 2, 2 (2012).

2. Boudou, T., Crouzier, T., Ren, K., Blin, G. \& Picart, C. Multiple functionalities of polyelectrolyte multilayer films: New biomedical applications. Adv. Mater. 22, 441-467 (2010).

3. Ding, I., Shendi, D. M., Rolle, M. W. \& Peterson, A. M. Growth-Factor-Releasing Polyelectrolyte Multilayer Films to Control the Cell Culture Environment. Langmuir 34, 1178-1189 (2018).

4. Peterson, A. M., Möhwald, H. \& Shchukin, D. G. PH-controlled release of proteins from polyelectrolyte-modified anodized titanium surfaces for implant applications.

Biomacromolecules 13, 3120-3126 (2012).

5. Peterson, A. M., Pilz-Allen, C., Kolesnikova, T., Möhwald, H. \& Shchukin, D. Growth factor release from polyelectrolyte-coated titanium for implant applications. ACS Appl. 
Mater. Interfaces 6, 1866-1871 (2014).

6. Guillot, R. et al. The stability of BMP loaded polyelectrolyte multilayer coatings on titanium. Biomaterials 34, 5737-5746 (2013).

7. Ceccaldi, C. et al. Evaluation of polyelectrolyte complex-based scaffolds for mesenchymal stem cell therapy in cardiac ischemia treatment. Acta Biomater. 10, 901911 (2014).

8. Calarco, A. et al. Controlled delivery of the heparan sulfate/FGF-2 complex by a polyelectrolyte scaffold promotes maximal hMSC proliferation and differentiation. J. Cell. Biochem. 110, 903-909 (2010).

9. Galderisi, U. et al. Efficient cultivation of neural stem cells with controlled delivery of FGF-2. Stem Cell Res. 10, 85-94 (2013).

10. She, Z., Wang, C., Li, J., Sukhorukov, G. B. \& Antipina, M. N. Encapsulation of basic fibroblast growth factor by polyelectrolyte multilayer microcapsules and its controlled release for enhancing cell proliferation. Biomacromolecules 13, 2174-2180 (2012).

11. Han, U. et al. Efficient encapsulation and sustained release of basic fibroblast growth factor in nanofilm: extension of the feeding cycle of human induced pluripotent stem cell culture. ACS Appl. Mater. Interfaces acsami.7b05519 (2017) doi:10.1021/acsami.7b05519.

12. Chu, H., Gao, J., Chen, C.-W., Huard, J. \& Wang, Y. Injectable fibroblast growth factor-2 coacervate for persistent angiogenesis. Proc. Natl. Acad. Sci. 108, 13444-13449 (2011).

13. Ding, I., Walz, J. A., Mace, C. R. \& Peterson, A. M. Early hMSC morphology and proliferation on model polyelectrolyte multilayers. Colloids Surfaces B Biointerfaces 178, 276-284 (2019). 
14. Sukhishvili, S. A., Kharlampieva, E. \& Izumrudov, V. Where Polyelectrolyte Multilayers and Polyelectrolyte Complexes Meet. Macromolecules 39, 8873-8881 (2006).

15. Salomäki, M., Vinokurov, I. A. \& Kankare, J. Effect of temperature on the buildup of polyelectrolyte multilayers. Langmuir 21, 11232-11240 (2005).

16. She, Z., Antipina, M. N., Li, J. \& Sukhorukov, G. B. Mechanism of Protein Release from Polyelectrolyte Multilayer. Biomacromolecules 11, 1241-1247 (2010).

17. Salvi, C., Lyu, X. \& Peterson, A. M. Effect of Assembly pH on Polyelectrolyte Multilayer Surface Properties and BMP-2 Release. Biomacromolecules 17, 1949-1958 (2016).

18. Zhang, H. et al. Effect of Polyelectrolyte Film Stiffness on Endothelial Cells during Endothelial-to-Mesenchymal Transition. Biomacromolecules 16, 3584-3593 (2015).

19. Garcia-Maya, M. et al. Ligand concentration is a driver of divergent signaling and pleiotropic cellular responses to FGF. J. Cell. Physiol. 206, 386-393 (2006).

20. Ahn, H.-J., Lee, W.-J., Kwack, K. \& Kwon, Y. Do. FGF2 stimulates the proliferation of human mesenchymal stem cells through the transient activation of JNK signaling. FEBS Lett. 583, 2922-6 (2009).

21. Page, R. L. et al. Induction of Stem Cell Gene Expression in Adult Human Fibroblasts without Transgenes. Cloning Stem Cells 11, 417-426 (2009).

22. Presta, M. et al. Fibroblast growth factor/fibroblast growth factor receptor system in angiogenesis. Cytokine Growth Factor Rev. 16, 159-178 (2005).

23. Narita, A. et al. Effect of gelatin hydrogel incorporating fibroblast growth factor 2 on human meniscal cells in an organ culture model. Knee 16, 285-289 (2009).

24. Almodóvar, J., Bacon, S., Gogolski, J., Kisiday, J. D. \& Kipper, M. J. Polysaccharidebased polyelectrolyte multilayer surface coatings can enhance mesenchymal stem cell 
response to adsorbed growth factors. Biomacromolecules 11, 2629-2639 (2010).

25. Crouzier, T., Fourel, L., Boudou, T., Albigès-Rizo, C. \& Picart, C. Presentation of BMP-2 from a soft biopolymeric film unveils its activity on cell adhesion and migration. $A d v$. Mater. 23, 111-118 (2011).

26. Shah, N. J. et al. Tunable dual growth factor delivery from polyelectrolyte multilayer films. Biomaterials 32, 6183-6193 (2011).

27. Müller, S. et al. VEGF-Functionalized Polyelectrolyte Multilayers as Proangiogenic Prosthetic Coatings. Adv. Funct. Mater. 18, 1767-1775 (2008).

28. Boura, C. et al. Endothelial cell—interactions with polyelectrolyte multilayer films. Biomaterials 26, 4568-4575 (2005).

29. Chaganti, L. K., Venkatakrishnan, N. \& Bose, K. An efficient method for FITC labelling of proteins using tandem affinity purification. Biosci. Rep. 38, 1-8 (2018).

30. Shiba, T. et al. Modulation of mitogenic activity of fibroblast growth factors by inorganic polyphosphate. J. Biol. Chem. 278, 26788-26792 (2003).

31. Kurien, B. \& Scofield, R. Western blotting. Methods 38, 283-293 (2006).

32. MacPhee, D. J. Methodological considerations for improving Western blot analysis. J. Pharmacol. Toxicol. Methods 61, 171-177 (2010).

33. Sakamoto, S. et al. Enzyme-linked immunosorbent assay for the quantitative/qualitative analysis of plant secondary metabolites. J. Nat. Med. 72, 32-42 (2018).

34. Sanchez-Ruiz, J. M. Protein kinetic stability. Biophys. Chem. 148, 1-15 (2010).

35. Shiratori, S. S. \& Rubner, M. F. pH-dependent thickness behavior of sequentially adsorbed layers of weak polyelectrolytes. Macromolecules 33, 4213-4219 (2000).

36. Sui, Z., Salloum, D. \& Schlenoff, J. B. Effect of molecular weight on the construction of 
polyelectrolyte multilayers: Stripping versus sticking. Langmuir 19, 2491-2495 (2003).

37. Siepmann, J. \& Peppas, N. A. Modeling of drug release from delivery systems based on hydroxypropyl methylcellulose (HPMC). Adv. Drug Deliv. Rev. 64, 163-174 (2012).

38. Kole, D., Ambady, S., Page, R. L. \& Dominko, T. Maintenance of Multipotency in Human Dermal Fibroblasts Treated with Xenopus laevis Egg Extract Requires Exogenous Fibroblast Growth Factor-2. Cell. Reprogram. 16, 18-28 (2014).

39. Dolivo, D. M., Larson, S. A. \& Dominko, T. FGF2-mediated attenuation of myofibroblast activation is modulated by distinct MAPK signaling pathways in human dermal fibroblasts. J. Dermatol. Sci. 88, 339-348 (2017).

40. Kole, D. et al. High molecular weight FGF2 isoforms demonstrate canonical receptormediated activity and support human embryonic stem cell self-renewal. Stem Cell Res. 21, 106-116 (2017).

41. Tew, L. S., Ching, J. Y., Ngalim, S. H. \& Khung, Y. L. Driving mesenchymal stem cell differentiation from self-assembled monolayers. RSC Adv. 8, 6551-6564 (2018).

42. Stephenson, M. \& Grayson, W. Recent advances in bioreactors for cell-based therapies. F1000Research 7, 517 (2018).

43. Malin Edvardsson. Why are overtones important in QCM? Biolin Scientific (2018).

44. Vogt, B. D., Lin, E. K., Wu, W. \& White, C. C. Effect of Film Thickness on the Validity of the Sauerbrey Equation for Hydrated Polyelectrolyte Films. J. Phys. Chem. B 108, 12685-12690 (2004).

45. Schneider, C. A., Rasband, W. S. \& Eliceiri, K. W. NIH Image to Image : 25 years of Image Analysis. Nat. Methods 9, 671-675 (2012).

\section{Acknowledgements}


Research was sponsored by the Office of the Secretary of Defense and was accomplished under Agreement Number W911NF-17-3-003. The views and conclusions contained in this document are those of the authors and should not be interpreted as representing the official policies, either expressed or implied, of the Office of the Secretary of Defense or the U.S. Government. The U.S. Government is authorized to reproduce and distribute reprints for Government purposes notwithstanding any copyright notation herein.

\section{Author Contribution Statement}

ID and AMP conceived and planned the experiments. ID carried out the experiments, took lead in the analysis of results, and wrote the initial draft of the manuscript. ID and AMP edited together to create the final version of the manuscript. AMP supervised the project.

\section{Competing Interests Statement}

The authors declare no competing interests.

\section{Legends}

Figure 1. a. ELISA-detectable FGF2 at high $(500 \mathrm{ng} / \mathrm{mL})$ and low $(250 \mathrm{ng} / \mathrm{mL})$ initial starting concentrations in both PBS and unmodified DMEM over the course of 4 days. Error bars represent standard deviation $(n=5)$. b. Natural logarithm of the same average concentration values with a linear fit from $8 \mathrm{~h}$ to $96 \mathrm{~h}$. The fit line is used to determine the degradation constant to calculate the half-life.

Figure 2. Cumulative FGF2 release over 4 days from FGF2-(PMAA/PLH) 5 PEMs. Error represents standard deviation $(\mathrm{n}=5)$. 
Figure 3. PEM mass during assembly obtained from QCM-D results for (PLH/PMAA) 5.5 $_{\text {PEMs }}$ assembled at a $\mathrm{pH}$ range from $\mathrm{pH}=4$ to $\mathrm{pH}=8$.

Figure 4. a. Modeled concentration of FGF2 released from PEMs. pH values refer to PEM assembly conditions. Model assumes a $1.9 \mathrm{~cm}^{2}$ surface area and $600 \mu \mathrm{L}$ of media. b. Modeled FGF2 concentrations assuming exogenous supplementation of FGF2 at $4 \mathrm{ng} / \mathrm{mL}$, and $8 \mathrm{ng} / \mathrm{mL}$, at both $\mathrm{t}=0$ and $\mathrm{t}=2$ days.

Figure 5. Representative images of cells stained with Hoechst 33342 (blue) and phalloidin coupled with Alexa Fluor 488 (green) at a. 2 days and b. 4 days of culture time. pH values refer to PEM assembly conditions.

Figure 6. Comparison between 2-day and 4-day results for a. cell counts obtained from Hoechst 33342 nuclear staining and b. average cell surface areas from phalloidin labeling. Error bars represent standard deviation $(\mathrm{n}=12)$. * represents statistical differences from PEM-only control of the same time point. ** represent statistical differences from all other conditions at the same time point. 


\section{Figures}
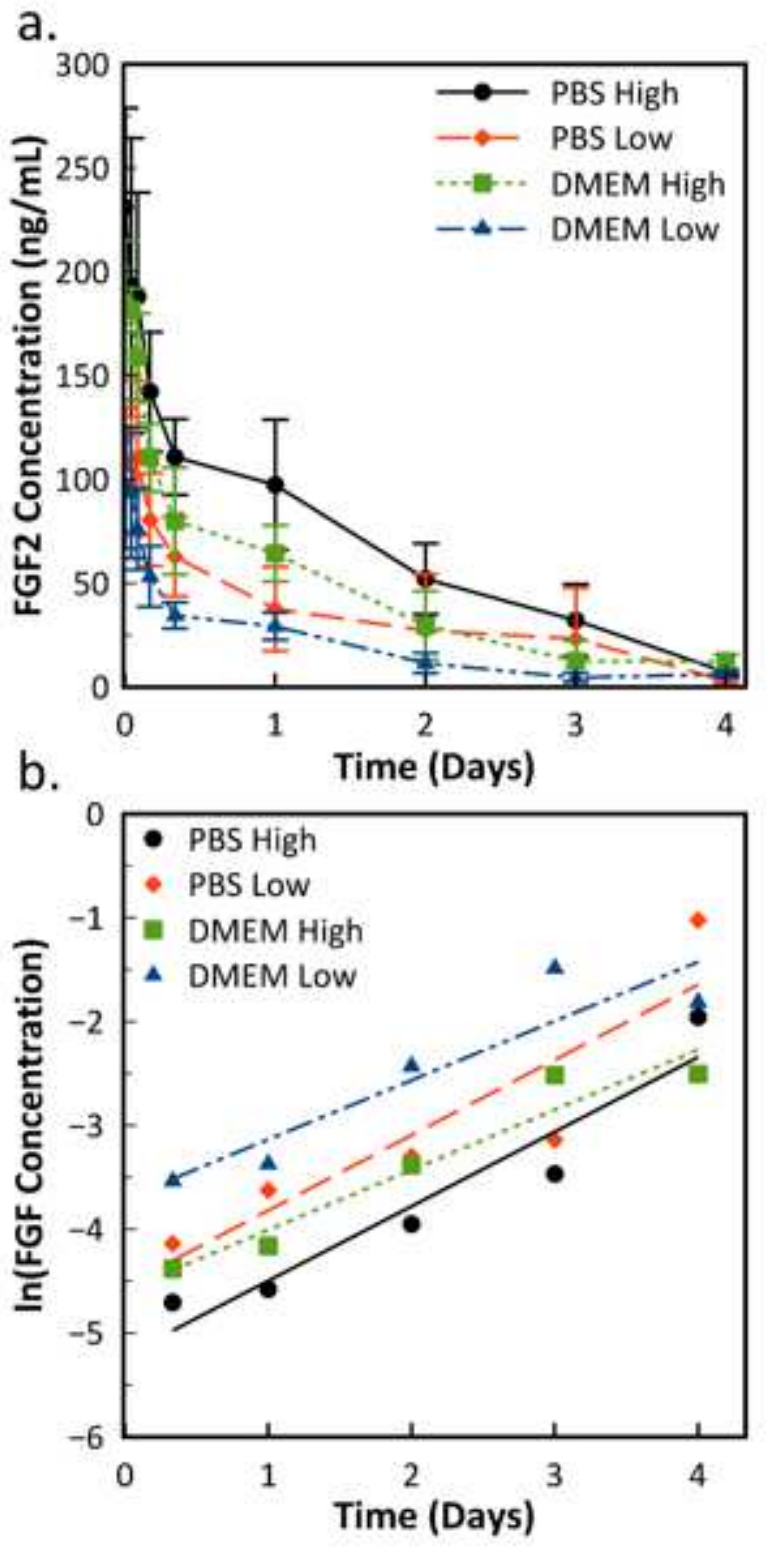

Figure 1

a. ELISA-detectable FGF2 at high $(500 \mathrm{ng} / \mathrm{mL})$ and low $(250 \mathrm{ng} / \mathrm{mL})$ initial starting concentrations in both PBS and unmodified DMEM over the course of 4 days. Error bars represent standard deviation $(n=5)$. b. Natural logarithm of the same average concentration values with a linear fit from $8 \mathrm{~h}$ to $96 \mathrm{~h}$. The fit line is used to determine the degradation constant to calculate the half-life. 


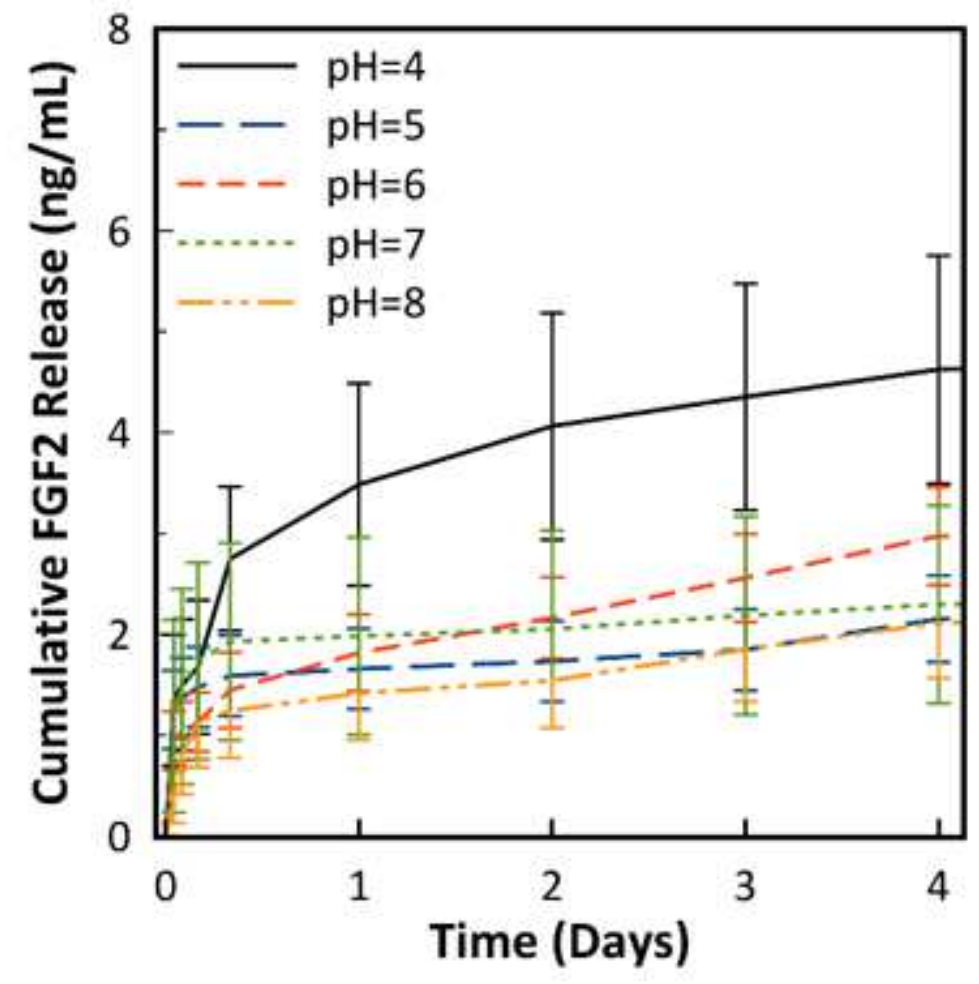

Figure 2

Cumulative FGF2 release over 4 days from FGF2-(PMAA/PLH) 5 PEMs. Error represents standard deviation $(n=5)$.

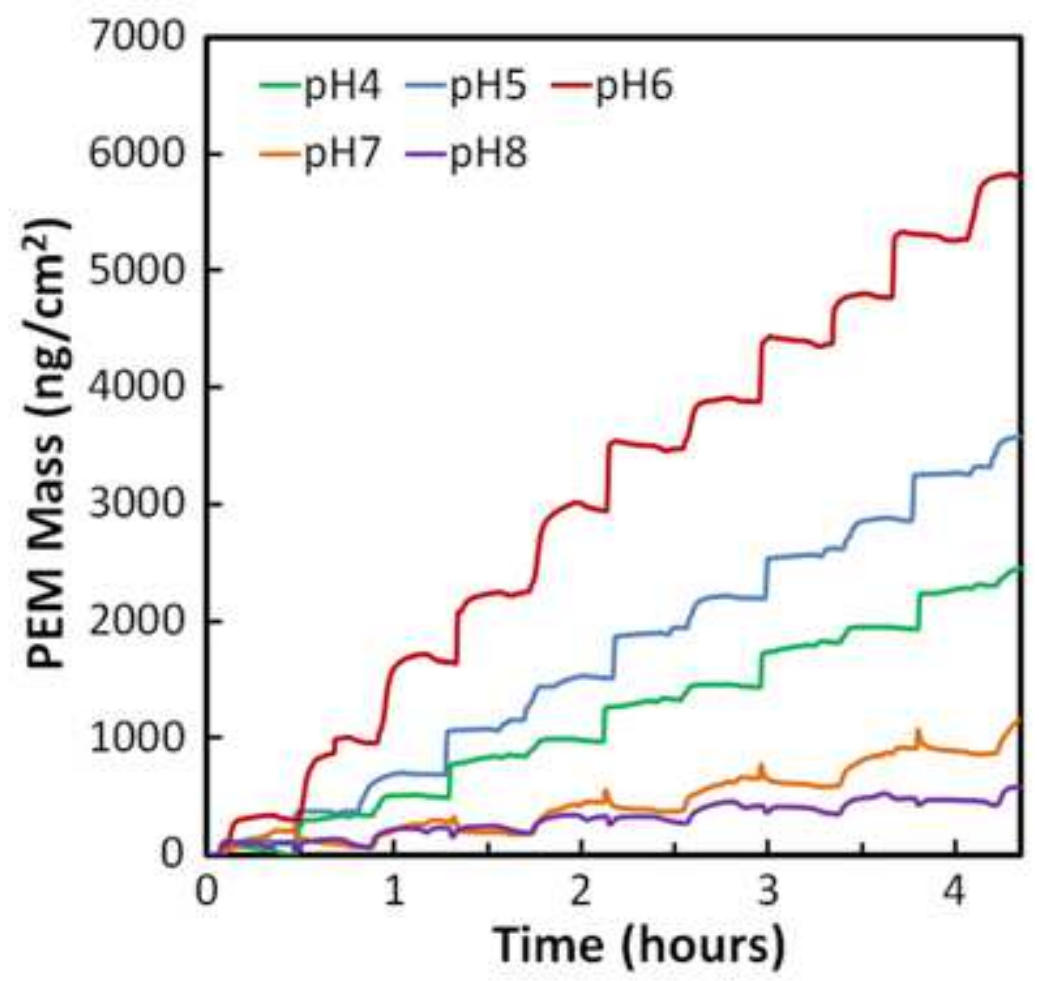


Figure 3

PEM mass during assembly obtained from QCM-D results for (PLH/PMAA) 5.5 PEMs assembled at a pH range from $\mathrm{pH}=4$ to $\mathrm{pH}=8$.
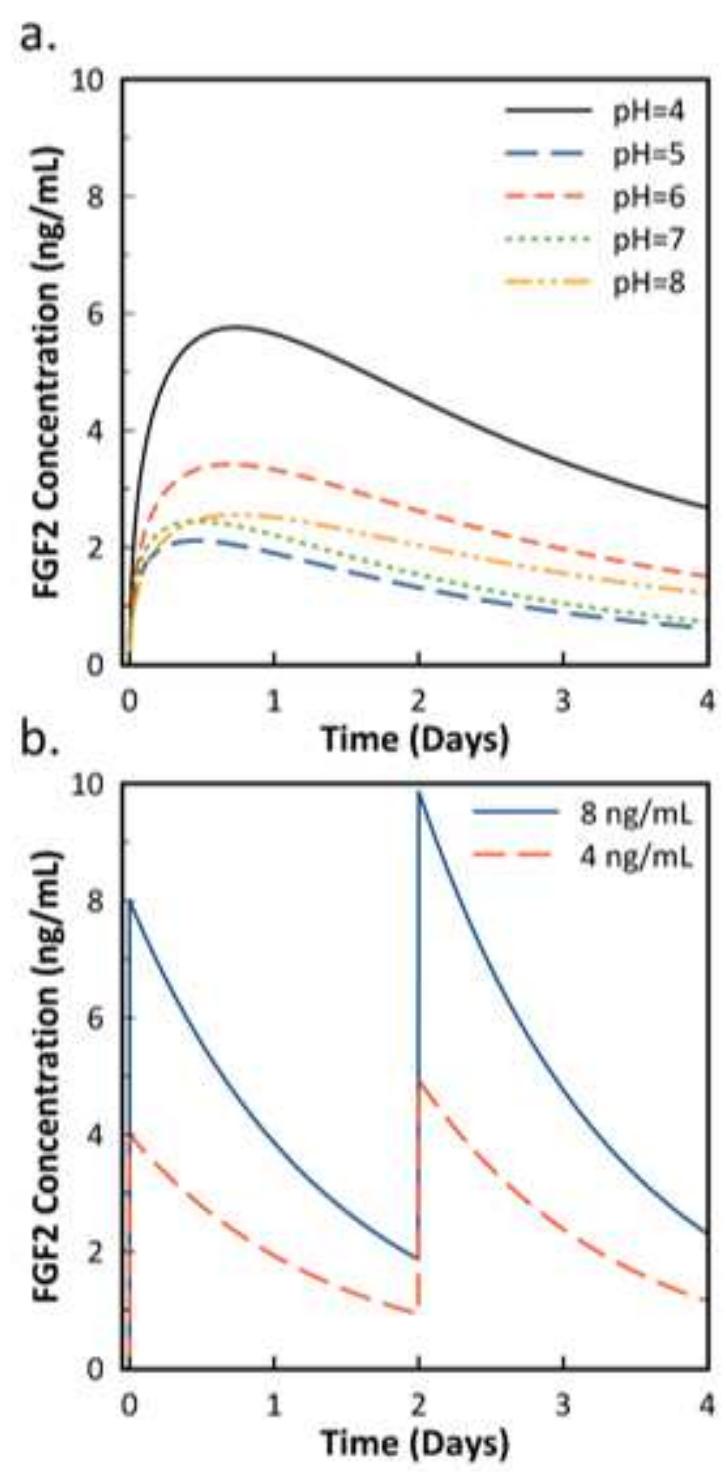

\section{Figure 4}

a. Modeled concentration of FGF2 released from PEMs. pH values refer to PEM assembly conditions. Model assumes a $1.9 \mathrm{~cm} 2$ surface area and $600 \mu \mathrm{L}$ of media. b. Modeled FGF2 concentrations assuming exogenous supplementation of FGF2 at $4 \mathrm{ng} / \mathrm{mL}$, and $8 \mathrm{ng} / \mathrm{mL}$, at both $\mathrm{t}=0$ and $\mathrm{t}=2$ days. 

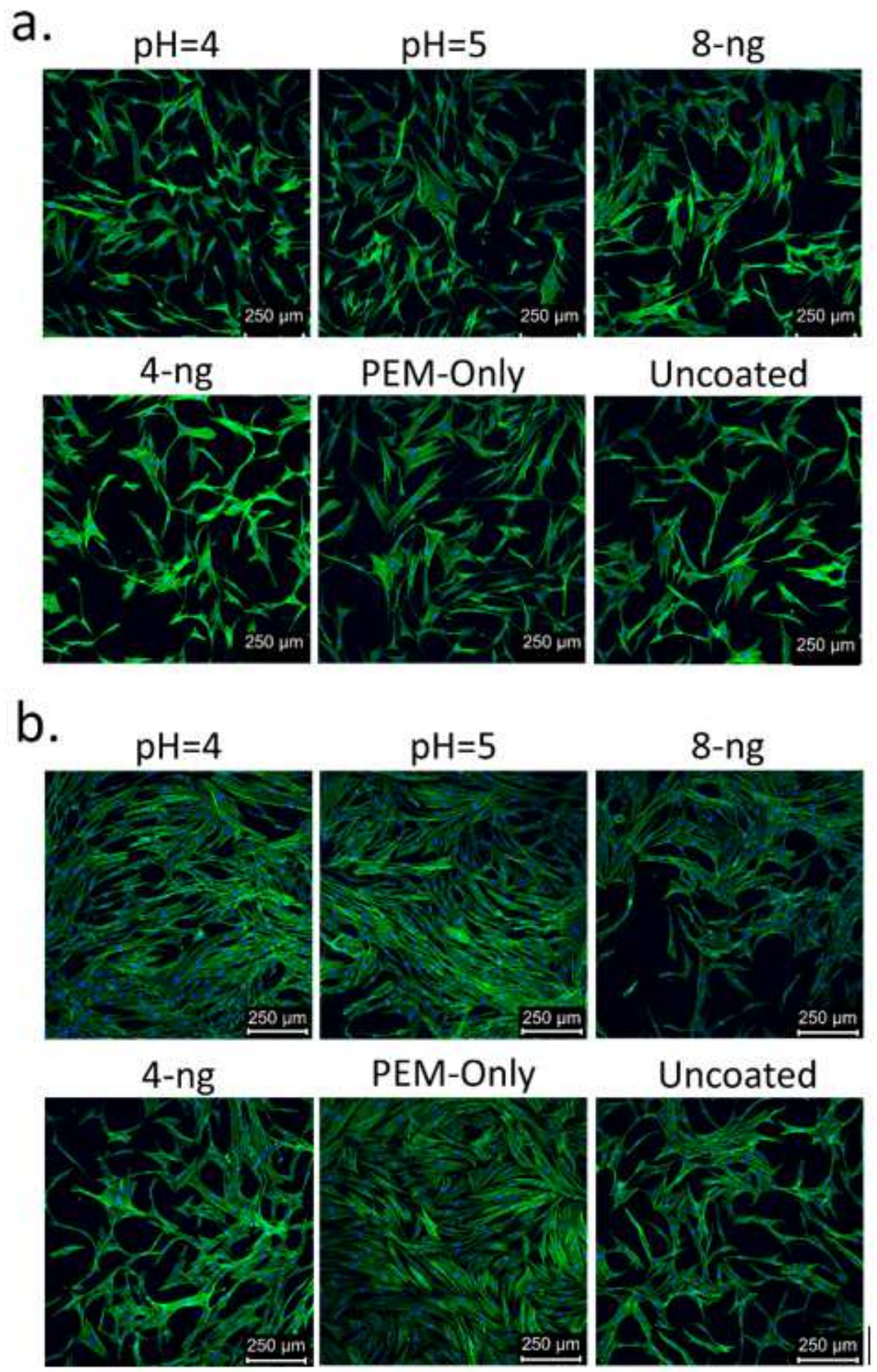

\section{Figure 5}

Representative images of cells stained with Hoechst 33342 (blue) and phalloidin coupled with Alexa Fluor 488 (green) at a. 2 days and b. 4 days of culture time. pH values refer to PEM assembly conditions. 

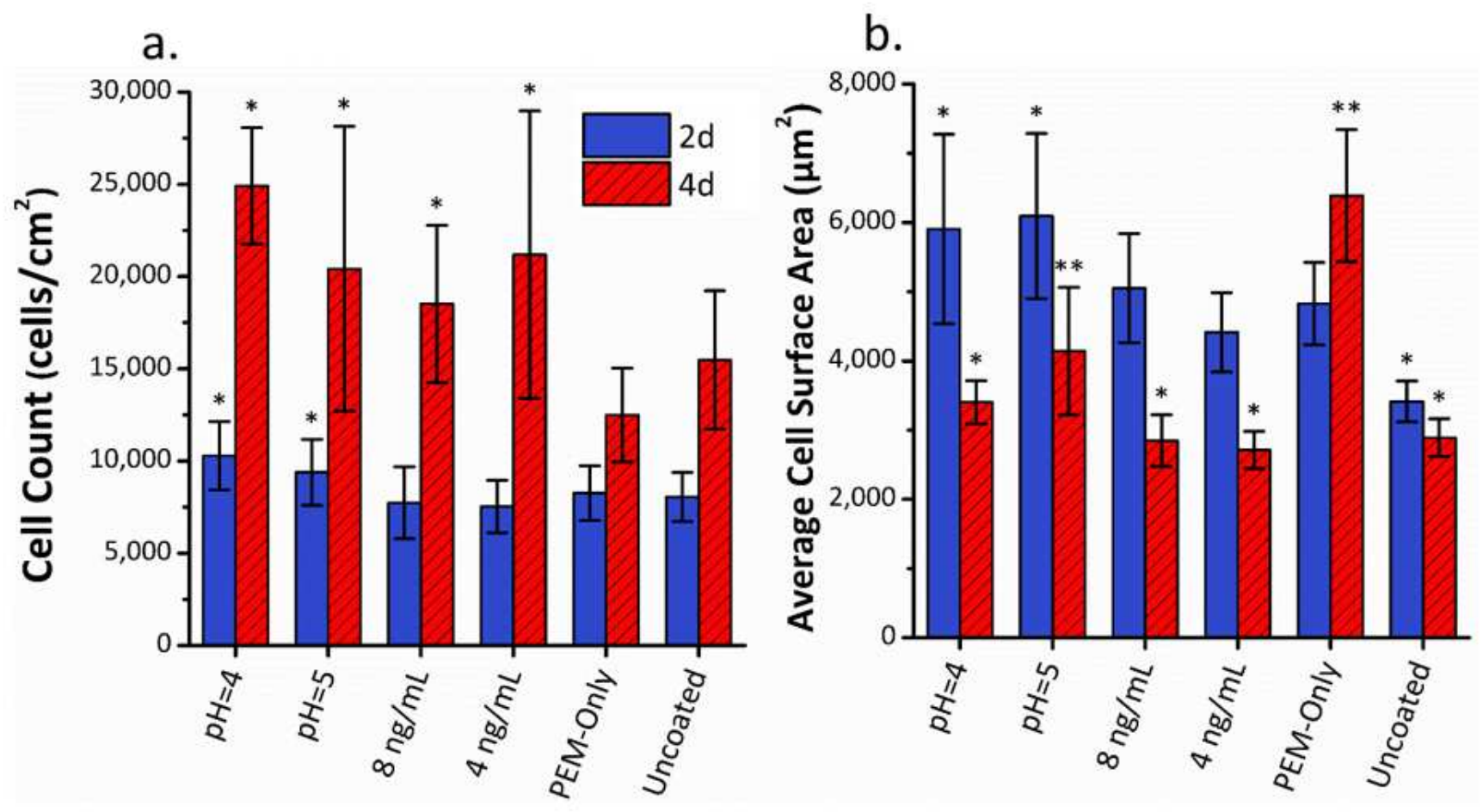

\section{Figure 6}

Comparison between 2-day and 4-day results for a. cell counts obtained from Hoechst 33342 nuclear staining and $b$. average cell surface areas from phalloidin labeling. Error bars represent standard deviation $(n=12)$. * represents statistical differences from PEM-only control of the same time point. ** represent statistical differences from all other conditions at the same time point.

\section{Supplementary Files}

This is a list of supplementary files associated with this preprint. Click to download.

- DingPetersonSupportinglnformation.docx 